\title{
CRESCIMENTO DE PORTA-ENXERTOS DE CITROS EM TUBETES INFLUENCIADOS POR DOSES DE $\mathrm{N}^{1}$
}

\author{
ANTÔNIO DECARLOS NETO², DALMO LOPES DE SIQUEIRA ${ }^{3}$, \\ PAULO ROBERTO GOMES PEREIRA ${ }^{3}$ E VICTOR HUGO ALVAREZ V. ${ }^{4}$
}

\begin{abstract}
RESUMO - Este trabalho teve como objetivo avaliar os efeitos de doses de $\mathrm{N}\left(0 ; 400 ; 800 ; 1.600 ; 3.200\right.$ e $4.800 \mathrm{mg} / \mathrm{dm}^{3} \mathrm{de} \mathrm{N}$ no substrato) sobre o crescimento de porta-enxertos de citros cultivados em tubetes. Os porta-enxertos limoeiros- 'Cravo' e 'Volkameriano' mostraram maior crescimento, sendo que as tangerineiras- 'Cleópatra' e 'Sunki' apresentaram crescimento intermediário, e o híbrido 'Tangelo-Orlando' exibiu crescimento inferior. A adição de doses crescentes de N, utilizando-se do fertilizante uréia em cobertura, promoveu acréscimos nos teores de $\mathrm{N}$-total na matéria seca da parte aérea destes porta-enxertos e aumento no crescimento dos portaenxertos. Aos 120 dias após a semeadura, o limoeiro- 'Cravo' apresentou altura máxima de $13,3 \mathrm{~cm}$ quando adubado com $1.240 \mathrm{mg} / \mathrm{dm}^{3}$ de N no substrato, sendo que o limoeiro-'Volkameriano' apresentou altura máxima de $12,3 \mathrm{~cm}$ adubado com $1.417 \mathrm{mg} / \mathrm{dm}^{3} \mathrm{de} \mathrm{N}$ no substrato. A tangerineira-'Cleópatra' apresentou altura máxima estimada de $12,0 \mathrm{~cm}$ quando adubada com $1.170 \mathrm{mg} / \mathrm{dm}^{3} \mathrm{de} \mathrm{N}$ no substrato, sendo que a tangerineira-'Sunki' apresentou altura de $10,1 \mathrm{~cm}$ adubada com $1.145 \mathrm{mg} / \mathrm{dm}^{3}$ de N no substrato, aos 120 dias após a semeadura. O híbrido 'Tangelo-Orlando' exibiu altura máxima de $9,1 \mathrm{~cm}$ quando foi aplicada a dose de $1.117 \mathrm{mg} / \mathrm{dm}^{3} \mathrm{de} \mathrm{N} \mathrm{no}$ substrato, aos 120 dias após a semeadura.
\end{abstract}

Termos para indexação: citros, viveiro, adubação, nutrição, nitrogênio

\section{CITRUS ROOTSTOCKS GROWTH ACCORDING TO N DOSES}

\begin{abstract}
The objective of this study was to evaluate the effects from $\mathrm{N}$ doses $\left(0 ; 400 ; 800 ; 1,600 ; 3,200 ;\right.$ and $4,800 \mathrm{mg} / \mathrm{dm}^{3}$ of $\mathrm{N}$ in substrate) on the growth of rootstocks lemons 'Cravo' and 'Volkameriano', tangerines 'Cleópatra' and 'Sunki', and hybrid 'TangeloOrlando' grown in tubules conditions. According to the results, the lemons presented a greater growth, the tangerines presented intermediate growth and the hybrid presented a lower growth. The addition of increasing $\mathrm{N}$ doses by application of the urea fertilizer, promoted increments in the growth of the rootstocks, and in the contents of total N. At 120 days after sowing, lemons 'Cravo' presented maximum height of $13.3 \mathrm{~cm}$ when fertilized using $1,240 \mathrm{mg} / \mathrm{dm}^{3}$ of $\mathrm{N}$ in substrate, whereas the lemon 'Volkameriano' presented maximum height of $12.3 \mathrm{~cm}$ when fertilized using $1,417 \mathrm{mg} / \mathrm{dm}^{3}$ of $\mathrm{N}$ in substrate. The 'Cleópatra' tangerine presented maximum height of $12.0 \mathrm{~cm}$ when fertilized using of $1,170 \mathrm{mg} / \mathrm{dm}^{3}$ of $\mathrm{N}$ in substrate, while the tangerine 'Sunki' presented a $10.1 \mathrm{~cm}$ height when fertilized using $1,145 \mathrm{mg} / \mathrm{dm}^{3}$ of $\mathrm{N}$ in substrate, at 120 days after sowing. The hybrid 'Tangelo-Orlando'presented a maximum height of $9.1 \mathrm{~cm}$ when a dose of $1,117 \mathrm{mg} / \mathrm{dm}^{3}$ of $\mathrm{N}$ was applied to substrate.
\end{abstract}

Index terms: citrus, nursery, manuring, nutrition , nitrogen

\section{INTRODUÇÃO}

A obtenção de porta-enxertos vigorosos e livres de patógenos na fase de sementeira é indispensável para a produção de mudas cítricas de alta qualidade. Modificações no processo tradicional de produção de mudas cítricas no Brasil, visando à melhoria na qualidade da muda, têm sido exigidas pelos órgãos fiscalizadores (NORMAS, 1998). Dentre estas modificações, destaca-se a utilização de tubetes como sementeiras a qual proporciona um sistema radicular volumoso com abundância de brotações de raízes laterais. As saliências laterais da superfície inferior dos tubetes impedem o enovelamento de raízes e estimulam o crescimento descendente das raízes laterais (CARVALHO, 1994; VICHIATO, 1996).
O crescimento de plantas em tubetes pode ser influenciado pelo volume limitado desse recipiente e pela fertilidade do substrato. Esta fertilidade depende dos componentes do substrato que preenche os recipientes (VICHIATO, 1996), sendo, normalmente, necessária a complementação da fertilidade natural do substrato com adubações de cobertura. Para SOUZA (1983), os substratos utilizados em recipientes são escolhidos em função da sua disponibilidade e de suas características físicas. Muitas vezes, substratos com baixos teores de nutrientes são utilizados, necessitando, assim, de complementação com adubações de cobertura.

Pesquisas realizadas com porta-enxertos (CARVALHO e SOUZA, 1996; CARVALHO, 1994; DECARLOS NETO et al.,

\footnotetext{
1 (Trabalho 020/2001). Recebido: 16/01/2001. Aceito para publicação: 14/11/2001. Apoio finaceiro do CNPq. Extraído da Dissertação apresentada pelo primeiro autor junto à Universidade Federal de Viçosa (UFV), para obtenção do título de Mestre.

2 Mestrando em Agronomia - Depto. de Fitotecnia UFV, Viçosa (MG) - CEP: 36570-000 - decarlos@zipmail.com

3 Prof. Dr. Depto. Fitotecnia UFV, Viçosa (MG) - CEP: 36570-000.

4 Prof. Dr. Depto. Solos UFV, Viçosa (MG) - CEP: 36570-000.
} 
1994; MAUST e WILIAMSON, 1994; OSENI e PAL, 1993) têm mostrado que há exigência nutricional diferenciada entre os portaenxertos de citros, com relação às adubações com nitrogênio. Entretanto, existe carência de informação sobre adubações de cobertura com $\mathrm{N}$ no sistema de obtenção de porta-enxertos de citros semeados em tubetes. Portanto, foi objetivo deste experimento avaliar o crescimento de alguns porta-enxertos de citros semeados em tubetes e adubados com diferentes doses de N.

\section{MATERIAL E MÉTODOS}

O experimento foi conduzido em casa de vegetação no Setor de Fruticultura da Universidade Federal de Viçosa (UFV), em Viçosa-MG, iniciado em setembro de 1995. As sementes foram extraídas de frutos maduros de plantas-matrizes dos portaenxertos Citrus limonia Osbeck, cv 'Cravo' (Cr); Citrus reshni Hort. ex Tan., cv 'Cleópatra' (Cl); Citrus sunki Hort. ex. Tan., cv 'Sunki' (Sk); Citrus volkameriana Hort. ex Tan., cv 'Volkameriano' (Vk); e Citrus paradisi Macf. x Citrus reticulata Blanco, cv 'Tangelo Orlando' (To). Os porta-enxertos foram semeados e cultivados num substrato composto de esterco de bovino + vermiculita expandida + terriço (1:1:1), enriquecido com $1,28 \mathrm{~kg} / \mathrm{m}^{3}$ de $\mathrm{P}_{2} \mathrm{O}_{5}$ no substrato; sendo utilizados como recipientes tubetes de plástico com diâmetro interno de $26 \mathrm{~mm}$ e comprimento de $126 \mathrm{~mm}$.

Foi utilizado o delineamento experimental em blocos casualizados, em esquema de parcelas subdivididas, com cinco repetições e unidade experimental com 12 plantas úteis. As parcelas foram compostas dos cinco diferentes porta-enxertos. As subparcelas foram compostas de seis doses de $\mathrm{N}(0 ; 400$; $800 ; 1.600 ; 3.200$ e $4.800 \mathrm{mg} / \mathrm{dm}^{3}$ de N no substrato). As doses de $\mathrm{N}$ foram parceladas em oito aplicações de cobertura com uréia, em intervalos de sete dias, via água de irrigação. Em cada adubação, foram aplicados $5 \mathrm{ml}$ de solução por tubete (com 40 $\mathrm{cm}^{3}$ de substrato). As adubações foram iniciadas após o desbaste das plantas nos tubetes, aos 63 dias após a semeadura.

Aos 120 dias após a semeadura, avaliaram-se: a altura; a proporção de plantas aptas ao transplantio, contando-se o número de plantas com altura superior a $10 \mathrm{~cm}$; diâmetro do caule; área foliar; massa da matéria seca da parte aérea (folha + caule); e massa da matéria seca das raízes dos porta-enxertos.

Nas amostras coletadas aos 120 dias após a semeadura, foram determinados o teores de N-orgânico e os de $\mathrm{N}^{-\mathrm{NO}_{3}}$ na matéria seca obtida da parte aérea dos porta-enxertos. O Norgânico foi dosado pelo método de Nessler, após a digestão sulfúrica, e $\mathrm{N}^{-\mathrm{NO}_{3}}$ foi dosado pelo método do ácido salicílico. $\mathrm{O}$ teor de $\mathrm{N}$-total foi obtido a partir da soma dos teores de $\mathrm{N}$-orgânico com os de $\mathrm{N}-\mathrm{NO}_{3}$.

Os dados coletados foram submetidos à análise de variância, e os fatores de variação foram testados pelo teste $\mathrm{F}$ (significância de $5 \%$ e $1 \%$ ). Foram estabelecidos contrastes ortogonais que analisaram as diferenças entre o híbrido 'Tangelo Orlando' com os demais porta-enxertos [(To) vs. $(\mathrm{Cr}+\mathrm{Vk}+\mathrm{Cl}+\mathrm{Sk})]$, diferenças dos limoeiros com as tangerineiras $[(\mathrm{Cr}+\mathrm{Vk})$ vs. $(\mathrm{Cl}+\mathrm{Sk})]$, diferenças entre os limoeiros $[(\mathrm{Cr})$ vs. $(\mathrm{Vk})]$ e diferenças entre as tangerineiras $[(\mathrm{Cl}) v s$. (Sk)]. Os efeitos da variável quantitativa (doses de $\mathrm{N}$ ) foram submetidos ao ajuste de equações de regressão, sendo que a significância dos coeficientes das equações de regressão ajustadas foi testada pelo teste F, calculado e corrigido conforme ALVAREZ V. (1985).

\section{RESULTADOS E DISCUSSÃO}

\section{- Crescimento dos porta-enxertos}

$\mathrm{Na}$ Tabela 1, são apresentadas as características de crescimento avaliadas nos porta-enxertos. Os limoeiros'Volkameriano' e 'Cravo' mostraram crescimentos superiores, para todas as características avaliadas, quando comparados com as tangerineiras-'Sunki' e 'Cleópatra'. Este crescimento mostrou ser significativo $(\mathrm{P}<0,01)$, conforme o resultado do contraste testado.

Os limoeiros- 'Cravo' e 'Volkameriano' mostraram semelhanças no crescimento em altura, proporção de plantas aptas ao transplantio, área foliar, matéria seca de raiz e parte aérea (Tabela 1); entretanto, o limoeiro- 'Volkameriano' mostrou diâmetro do caule superior ao limoeiro 'Cravo'. As tangerineiras'Cleópatra' e 'Sunki' apresentaram semelhanças no diâmetro do caule, matéria seca de raiz e parte aérea (Tabela 1); entretanto, o crescimento em altura e a proporção de plantas aptas ao transplantio, apresentada pela tangerineira-'Cleópatra', mostrou ser superior $(\mathrm{P}<0,05)$ à da tangerineira-'Sunki', conforme o teste dos contrastes. A área foliar da tangerineira-'Sunki' foi superior $(\mathrm{P}<0,01)$ à da tangerineira- 'Cleópatra', conforme o teste dos contrastes. Já o híbrido 'Tangelo-Orlando' exibiu crescimento inferior $(\mathrm{P}<0,01)$ ao conjunto dos demais porta-enxertos, para a maioria das características avaliadas.

O maior vigor de crescimento dos limoeiros mostra, portanto, a maior rapidez destes porta-enxertos em atingirem o ponto de transplantio, quando comparados com as tangerineiras e o híbrido. Este resultado está de acordo com os encontrados por CARVALHO e SOUZA (1996), onde estes autores constataram maior crescimento do limoeiro- 'Cravo' em relação à tangerineira-'Cleópatra'.

\section{- Crescimento dos porta-enxertos em função das doses de $\mathbf{N}$}

A aplicação de doses de $\mathrm{N}$, utilizando uréia em cobertura, favoreceu significativamente $(\mathrm{P}<0,01)$ o crescimento em altura, diâmetro do caule, área foliar, acúmulo da massa de matéria seca da parte aérea e de raízes, e na proporção de plantas aptas ao transplantio dos porta-enxertos, aos 120 dias após a semeadura.

Na Figura 1, observa-se que, conforme se aumentaram as doses de $\mathrm{N}$ aplicadas, ocorreu um aumento da altura dos porta-enxertos. O porta-enxerto 'Tangelo-Orlando' exibiu altura máxima estimada de $9,1 \mathrm{~cm}$ quando foi aplicada a dose de 1.117 $\mathrm{mg} / \mathrm{dm}^{3}$ de $\mathrm{N}$ no substrato, não atingindo a altura ideal de transplantio $(10 \mathrm{~cm})$ aos 120 dias após a semeadura. Os limoeiros'Cravo' e 'Volkameriano' apresentaram altura máxima estimada de 13,3 e $12,3 \mathrm{~cm}$ quando adubados com 1.240 e $1.417 \mathrm{mg} / \mathrm{dm}^{3} \mathrm{de}$ $\mathrm{N}$ no substrato, respectivamente, atingindo a altura ideal de transplantio aos 120 dias após a semeadura. As tangerineiras'Cleópatra' e 'Sunki' apresentaram alturas estimadas de 12,0 e $10,1 \mathrm{~cm}$ quando adubadas com as doses de 1.170 e $1.145 \mathrm{mg} / \mathrm{dm}^{3}$ de $\mathrm{N}$ no substrato, respectivamente, atingindo a altura ideal de transplantio aos 120 dias após a semeadura.

Houve efeito depressivo das altas doses de N ( 3.200 e 
$4.800 \mathrm{mg} / \mathrm{dm}^{3}$ de N no substrato) sobre a altura dos porta-enxertos aos 120 dias após a semeadura (Figura 1). Este efeito depressivo pode ter ocorrido devido à diminuição do $\mathrm{pH}$ do substrato, através da liberação de $\mathrm{H}^{+}$produzidos durante o processo de nitrificação da uréia aplicada. Efeitos depressivos causados por altas doses de fertilizantes nitrogenados foram descritos por CARVALHO e SOUZA(1996), CALVERT (1969), CARVALHO(1994), MAUST e WILIAMSON (1994) e DECARLOS NETO et al. (1994).

\section{- Teor de N-total na parte aérea dos porta-enxertos em função das doses de $\mathbf{N}$}

Pelas equações de regressão (Figura 2), observa-se que, com o aumento das doses de $\mathrm{N}$ aplicadas, ocorreu aumento significativo $(\mathrm{P}<0,01)$ nos teores de $\mathrm{N}$-total na matéria seca da parte aérea dos porta-enxertos, aos 120 dias após a semeadura.

O cultivo de porta-enxertos de citros, quando semeados em tubete, mostrou necessitar de adubações de cobertura com

TABELA 1 - Valores médios ${ }^{(1)}$ da altura, proporção de plantas aptas ao transplantio, diâmetro, área foliar, massa da matéria seca da parte aérea e das raízes dos porta-enxertos ‘Tangelo-Orlando', 'Cravo', 'Volkameriano', 'Cleópatra' e 'Sunki', medidos aos 120 dias após a semeadura

$\begin{array}{lll}\text { Característica } & \text { Unid. } & \text { Porta-enxertos }\end{array}$

'T. Orlando' 'Cravo' 'Volkameriano' 'Cleópatra' 'Sunki'

\begin{tabular}{lcccccc}
\hline Altura das plantas & $(\mathrm{cm})$ & 7,6 & 11,3 & 10,9 & 9,8 & 8,5 \\
Plantas aptas ao transplantio & $(\%)$ & 41 & 82 & 74 & 68 & 54 \\
Diâmetro do caule & $(\mathrm{mm})$ & 2,0 & 2,3 & 2,5 & 1,9 & 1,9 \\
Área foliar & $\left(\mathrm{cm}^{2}\right)$ & 49,5 & 76,3 & 77,4 & 45,0 & 63,7 \\
Matéria seca de raiz & $(\mathrm{g})$ & 0,18 & 0,24 & 0,26 & 0,12 & 0,12 \\
Matéria seca da parte aérea & $(\mathrm{g})$ & 0,49 & 0,66 & 0,59 & 0,46 & 0,58 \\
\hline
\end{tabular}

(1): valores médios das doses de $\mathrm{N}$.

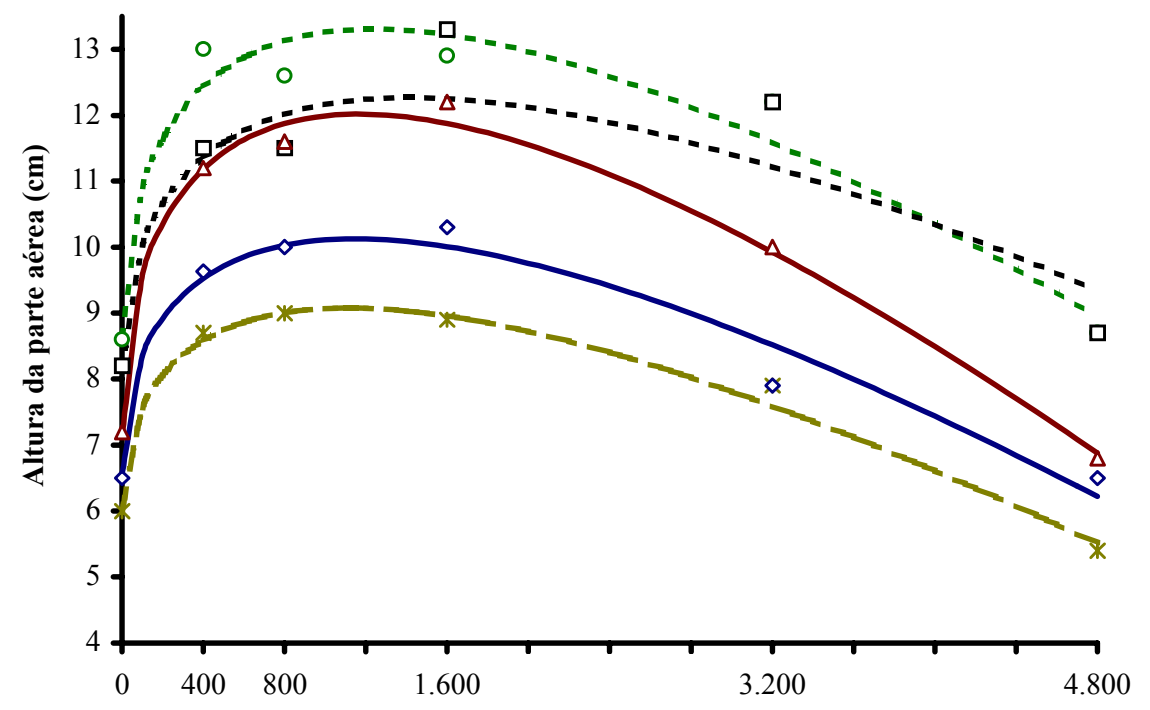

$\mathbf{m g} / \mathrm{dm}^{3}$ de $\mathrm{N}$ no substrato

\begin{tabular}{llll|}
\hline$\rightarrow-$ & 'Tângelo Orlando' & $\hat{\mathrm{Y}}=5,998+0,1846^{* *} \sqrt{\mathrm{N}}-0,002765^{* *} \mathrm{~N}$ & $\left(\mathrm{R}^{2}=0,98\right)$ \\
$-0-$ & 'Cravo' & $\hat{\mathrm{Y}}=8,6514+0,2644^{* *} \sqrt{\mathrm{N}}-0,003753^{* *} \mathrm{~N}$ & $\left(\mathrm{R}^{2}=0,94\right)$ \\
$-\square-$ & 'Volkameriano' & $\hat{\mathrm{Y}}=8,1332+0,21964^{* *} \sqrt{\mathrm{N}}-0,002917^{* *} \mathrm{~N}$ & $\left(\mathrm{R}^{2}=0,84\right)$ \\
$\longrightarrow \square$ & 'Cleópatra' & $\hat{\mathrm{Y}}=7,1597+0,2849^{* *} \sqrt{\mathrm{N}}-0,004164^{* *} \mathrm{~N}$ & $\left(\mathrm{R}^{2}=0,99\right)$ \\
$\longrightarrow-$ 'Sunki' & $\hat{\mathrm{Y}}=6,565+0,2104^{* *} \sqrt{\mathrm{N}}-0,003109^{* *} \mathrm{~N}$ & $\left(\mathrm{R}^{2}=0,97\right)$ \\
\hline
\end{tabular}

FIGURA 1 - Alturas dos porta-enxertos ‘Tangelo-Orlando', 'Cravo', 'Volkameriano', 'Cleópatra' e 'Sunki', medidas aos 120 dias após a semeadura, em função das doses de $\mathrm{N}$. 
TABELA 2 - Faixa ${ }^{(1)}$ do teor adequado de N-total da matéria seca da parte aérea dos porta-enxertos 'Tangelo-Orlando', 'Cravo', 'Volkameriano', 'Cleópatra' e 'Sunki', determinada aos 120 dias após a semeadura

\begin{tabular}{lc}
\hline & Teor de N-total da matéria seca da parte aérea \\
\cline { 2 - 2 } Porta-enxerto & Adequado \\
\hline 'Tangelo-Orlando' & $-\mathrm{-g} / \mathrm{kg}-\mathrm{--}$ \\
'Cravo' & $20-24$ \\
'Volkameriano' & $18-22$ \\
'Cleópatra' & $19-24$ \\
'Sunki' & $17-20$ \\
\hline
\end{tabular}

(1): Faixa determinada para $90 \%$ e $100 \%$ do crescimento máximo em altura dos porta-enxertos.

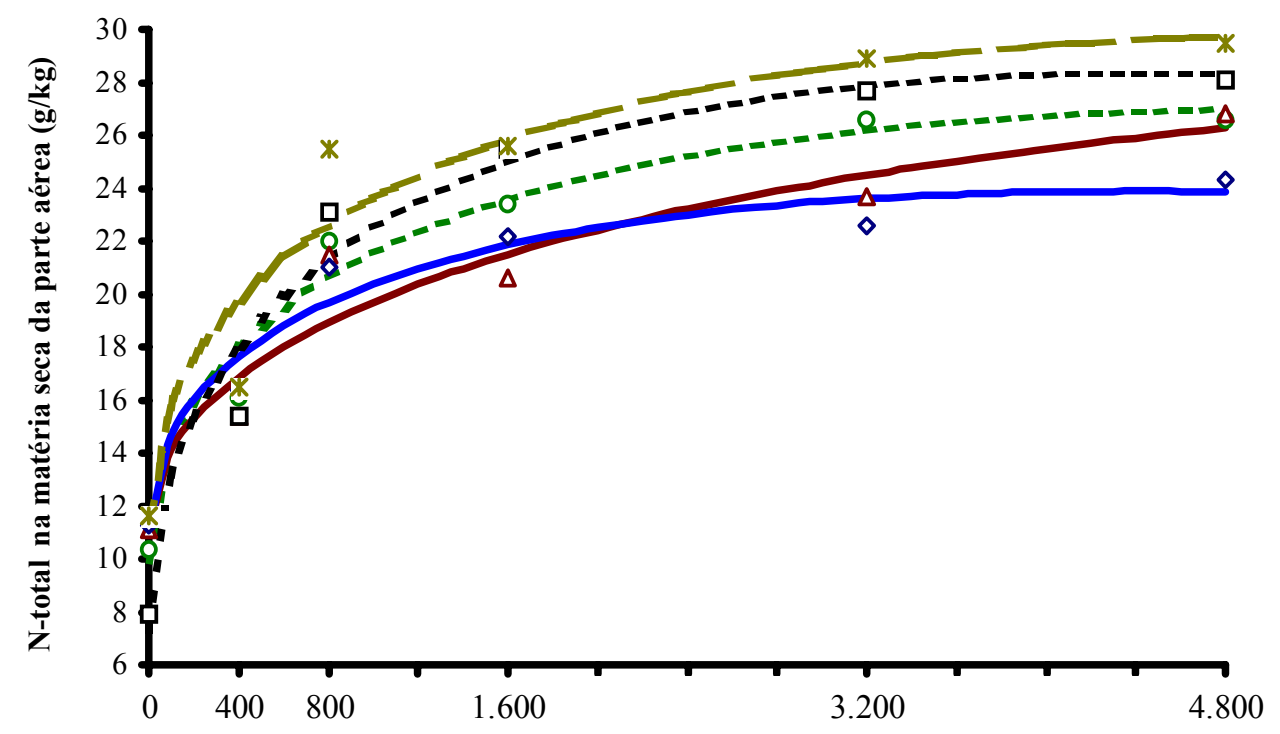

$\mathrm{mg} / \mathrm{dm}^{3}$ de $\mathrm{N}$ no substrato

\begin{tabular}{|c|c|c|c|}
\hline $\begin{array}{r}*= \\
-0= \\
-\square= \\
-\Delta-\end{array}$ & $\begin{array}{l}\text { 'Tângelo Orlando' } \\
\text { 'Cravo' } \\
\text { 'Volkameriano' } \\
\text { 'Cleópatra' } \\
\text { 'Sunki' }\end{array}$ & $\begin{array}{l}\hat{Y}=10,94+0,5092^{* *} \sqrt{N}-0,003440^{* *} N \\
\hat{Y}=9,86+0,4710^{* *} \sqrt{N}-0,003238^{* *} N \\
\hat{Y}=7,30+0,6300^{* *} \sqrt{N}-0,004716^{* *} N \\
\hat{Y}=11,09+0,3156 \sqrt[*]{N}-0,001391^{* *} N \\
\hat{Y}=11,11+0,3843^{* *} \sqrt{N}-0,002890^{* *} N\end{array}$ & $\begin{array}{l}\left(R^{2}=0,93\right) \\
\left(R^{2}=0,97\right) \\
\left(R^{2}=0,97\right) \\
\left(R^{2}=0,94\right) \\
\left(R^{2}=0,96\right)\end{array}$ \\
\hline
\end{tabular}

FIGURA 2 - Teores de N-total na matéria seca da parte aérea dos porta-enxertos 'Tangelo-Orlando', 'Cravo', 'Volkameriano', 'Cleópatra' e 'Sunki', determinados aos 120 dias após a semeadura, em função das doses de N.

$\mathrm{N}$, visto que os porta-enxertos que não receberam as adubações com uréia $\left(0 \mathrm{mg} / \mathrm{dm}^{3}\right.$ de $\mathrm{N}$ no substrato), apresentaram baixos teores de N-total (Figura 2), mostrando menor desenvolvimento em altura (Figura 1) e cloroses generalizadas nas folhas, indicando os sintomas visuais de deficiência de nitrogênio.

$\mathrm{Na}$ Tabela 2, estão apresentadas as faixas dos teores adequados de $\mathrm{N}$-total de cada porta-enxerto testado. Os teores adequados de N-total dos porta-enxertos 'Cravo' e Cleópatra,' obtidos neste estudo, estão próximos aos encontrados por
CARVALHO (1994). Em termos práticos, a faixa do teor adequado de N-total, na matéria seca da parte aérea dos porta-enxertos, representa uma condição ótima de crescimento dos portaenxertos, podendo ser utilizada como critério da necessidade de $\mathrm{N}$, auxiliando no manejo da adubação nitrogenada dos portaenxertos cultivados em tubetes.

Diante dos resultados obtidos neste experimento, as adubações de cobertura com uréia mostraram influenciar positivamente no crescimento e nos teores de $\mathrm{N}$-total da parte 
aérea dos porta-enxertos testados. Entretanto, deve ser ressaltada a necessidade do manejo adequado desta adubação, devido aos efeitos depressivos das altas doses de N (3.200 e $4.800 \mathrm{mg} / \mathrm{dm}^{3} \mathrm{~N}$ de substrato) sobre o crescimento dos portaenxertos.

\section{CONCLUSÕES}

1. A utilização de tubetes como sementeira de portaenxertos de citros mostrou ser viável, proporcionando rápido crescimento destes na fase de sementeira. Os limoeiros- 'Cravo' e 'Volkameriano' exibiram maior crescimento quando comparados com as tangerineiras- 'Cleópatra' e 'Sunki' e o híbrido 'TangeloOrlando', aos 120 dias após a semeadura, mostrando, portanto, a maior rapidez dos limoeiros em atingir o ponto de transplantio.

2. As adubações com uréia, parceladas em oito aplicações a cada sete dias, influenciaram positivamente no crescimento dos porta-enxertos nos tubetes, podendo ser utilizadas como adubações de cobertura de $\mathrm{N}$ em porta-enxertos semeados em tubetes.

3. A fertilização dos porta-enxertos 'Cravo', 'Volkameriano', 'Cleópatra', 'Sunki' e 'Tangelo-Orlando', respectivamente com 1.240;1.417; 1.170; 1.145 e $1.117 \mathrm{mg} / \mathrm{dm}^{3}$ de $\mathrm{N}$ no substrato de cultivo, proporcionou o máximo crescimento em altura desses porta-enxertos, aos 120 dias após a semeadura. Entretanto, adubações excessivas com uréia (3.200 e $4.800 \mathrm{mg} /$ $\mathrm{dm}^{3}$ de $\mathrm{N}$ no substrato) causaram efeitos depressivos ao crescimento dos porta-enxertos.

\section{REFERÊNCIAS BIBLIOGRÁFICAS}

ALVAREZ V, V. H. Avaliação da fertilidade do solo. Viçosa: UFV , $1985.75 \mathrm{p}$.

CARVALHO, S. A. Manejo da adubação nitrogenada na produção de porta-enxertos cítricos em bandejas. 1994. 74f. Tese (Doutorado em Fitotecnia) - Escola Superior de Agricultura de Lavras, Lavras, 1994.
CARVALHO, S. A.; SOUZA, M. Doses e freqüência de aplicação de nitrato de potássio no crescimento do limoeiro- 'Cravo' e da tangerineira- 'Cleópatra' em bandejas. Pesquisa Agropecuária Brasileira, Brasília, v. 31, n. 11, p. 815-822, 1996.

CALVERT, D. V. Spray aplications of potassium nitrate for citrus on calcareous soils. In: INTERNATIONAL CITRUS SYMPOSIUM, 1968, Riverside. Proceedings ... Riverside : University of California ,1969. v.3, p.1587-1597.

DECARLOS NETO, A.; DE GRANDI, A. J.; VICHIATO, M.; DO AMARAL, A. M.; SOUZA, M. Viabilização do uso de tubetes para obter o porta-enxerto de citros limoeiro-'Cravo' com "solução de arranque". In: CONGRESSO BRASILEIRO DE FRUTICULTURA, 8, 1994, Salvador. Anais ... p.400-401 .

MAUST, B. E.; WILLIAMSON, J. G. Nitrogen nutrition of containerized citrus nursery plants. Journal of the American Society for Horticultural Science, Alexandria, v, 119, n. 2, p. 95201, 1994.

NORMAS para produção de mudas certificadas de citros. Laranja, Cordeirópolis, SP, v. 19, n. 12 p. 411-421, 1998.

OSENI, T. O.; PAL, U. R. Spacing and nitrogen requirement of citrus-nursery plants in Nigeria. Indian Journal of Agricultural Sciences, New Delhi, v. 63, n. 12, p. 781-785, 1993.

SOUZA, M. Nutrição e adubação para produzir mudas frutíferas. Informe Agropecuário, Belo Horizonte, v. 9, n. 102, p. 40-43, 1983.

VICHIATO, M. Influência da fertilização do porta-enxerto tangerineira (Citrus reshni Hort. ex Tan. cv. Cleópatra) em tubetes, até a repicagem. 1996. 82p. Dissertação (Mestrado em Fitotecnia) - Universidade Federal de Lavras, Lavras, 1996. 